\title{
In Vitro Evaluation of the Activity of Gemcitabine-Loaded Pegylated Unilamellar Liposomes Against Papillary Thyroid Cancer Cells
}

\author{
Margherita Vono ${ }^{1}$, Donato Cosco ${ }^{1}$, Christian Celia ${ }^{1}$, Donatella Paolino ${ }^{2}$, Marilena Celano ${ }^{1}$, \\ Diego Russo ${ }^{1}$ and Massimo Fresta ${ }^{1, *}$
}

\author{
${ }^{I}$ Department of Pharmacobiological Sciences, University "Magna Gracia" of Catanzaro, Campus Universitario \\ "S. Venuta" - Building of BioSciences, Viale Salvatore Venuta, I-88100 Germaneto (CZ), Italy \\ ${ }^{2}$ Department of Experimental and Clinical Medicine, University "Magna Gracia" of Catanzaro, Campus Universitario \\ "S. Venuta" - Building of BioSciences, Viale Salvatore Venuta, I-88100 Germaneto (CZ), Italy
}

\begin{abstract}
Papillary carcinoma is the most common form of malignant thyroid tumor. At present, a subset of these tumors are poorly responsive to the current treatment. Gemcitabine is a pyrimidine analog active against different types of solid tumors, but its use is limited by its short half-life. To improve the therapeutic effectiveness of this drug, gemcitabineloaded unilamellar pegylated liposomes were prepared and investigated against two human papillary thyroid carcinoma cell lines, i.e. TPC-1 and B-CPAP cells. The $\mathrm{pH}$ gradient drug encapsulation followed by the membrane extrusion technique were used to achieve unilamellar liposomes characterized by a mean size of $\sim 200 \mathrm{~nm}$, a polydispersity index of 0.02 and a zeta potential of $-1.7 \mathrm{mV}$. The gemcitabine was released from liposomes following a biphasic profile. The liposomal encapsulated gemcitabine showed an increased cytotoxic activity compared to the free drug against both thyroid carcinoma cell lines, as a consequence of the better drug internalization favored by the vesicular device. These findings demonstrate the advantage of channeling gemcitabine by liposomes suggesting a promising role for such a pharmaceutical formulation in the treatment of refractory papillary thyroid carcinoma.
\end{abstract}

Keywords: Pegylated unilamellar liposomes, anticancer drug delivery, gemcitabine, papillary thyroid carcinoma, in vitro antiproliferative activity, cell culture.

\section{INTRODUCTION}

Thyroid cancer is the most common neoplasm of the endocrine system, accounting for approximately $1 \%$ of all malignancies in Western countries [1], with an observed increasing incidence in the last decade [2,3]. The papillary histotype is the most frequent form (about $70 \%$ of cases) and generally maintains a well differentiated phenotype, including the ability to uptake the iodine after TSH stimulation [4, 5]. Thus, the use of radioiodine allows a good prognosis even in the presence of recurrent and metastatic disease [5]. However, a subset of these tumors (about 30\%), and their distant metastases, show a loss of differentiation markers, mainly the sodium/iodide symporter and the TSH receptor [6]. The inability to use the radioiodine make the prognosis of these tumors very poor, because of the low results obtained with the current approaches based on combination of surgery, chemotherapy and external radiotherapy [7]. The effectiveness of the anticancer drugs currently adopted, in fact, is largely limited by their toxicity, so that novel therapeutic strategies, including novel drugs and/or a better 'targeted' delivery to cancer cells, are under investigation [8].

\footnotetext{
*Address correspondence to this author at the Department of Pharmacobiological Sciences, University "Magna Græcia" of Catanzaro, Campus Universitario "S. Venuta" - Building of BioSciences, Viale Salvatore Venuta, I-88100 Germaneto (CZ), Italy; Tel: +39 0961369 4118; Fax: +390961 369 4237; E-mail: fresta@unicz.it
}

Among the chemotherapeutics with low systemic toxicity, gemcitabine $\left(2^{\mathrm{I}}, 2^{\mathrm{I}}\right.$-difluorodeoxycytidine $)$ is a deoxycytidine analog currently used as first-choice drug in pancreas metastatic cancer, non-small cell lung cancer and ovarian, bladder, neck and head cancer [9]. It has been tested with promising results in preclinical studies against poorly differentiated human thyroid carcinoma cell lines [10,11] and also in clinical trials in patients with anaplastic thyroid carcinoma with contrasting results [12,13]. A major limit for the use of gemcitabine is represented by its rapid metabolic inactivation (deamination operated by deoxicytidine deaminase) responsible for its short half-life together with its low but still important systemic toxicity [14].

In order to overcome these drawbacks and to increase gemcitabine activity, many approaches have been tried. Namely, the synthesis (Eli-Lilly patented) of saturated and monounsaturated $\mathrm{C} 18$ and $\mathrm{C} 20$ long chain 4-(N)-acylderivatives and $5^{\mathrm{I}}$-esters of gemcitabine, elicited an increase of the drug cytotoxic activity $[15,16]$. Another approach was based on the bio-conjugation of gemcitabine with poly (ethylene glycol) (PEG) and folic acid moieties. acting as polymeric drug carrier for the active targeting therapy of cancer disease over-expressing the folate receptor [17]. Another successful strategy to ameliorate the biopharmaceutical properties of the hydrophilic compound was the use of colloidal drug carriers and, particularly, of vesicular delivery systems, i.e. liposomes. 
Liposomal encapsulation of gemcitabine can provide protection against its rapid metabolic inactivation but lowmolecular-weight water-soluble drugs, just like gemcitabine, diffuse rapidly through phospholipid bilayers thus limiting the utility of this drug delivery system. To overcome this problem, gemcitabine was entrapped in liposomes by generating an acid gradient in the internal aqueous compartment that elicits the protonation of the drug, the formation of an poorly water-soluble salt and hence its retention within the carrier [11]. Furthermore, the pegylation of the liposome surface can contribute to reduce the gemcitabine diffusion, beside to provide blood long circulating feature following the i.v. administration of the liposome carrier.

In previous studies, we have demonstrated the effectiveness of the gemcitabine-loaded pegylated unilamellar liposomes as anticancer agents against multiple myeloma [18], pancreatic cancer [19] and anaplastic thyroid carcinoma cell lines $[11,20]$. In this work, the cytotoxic activity of gemcitabine-loaded unilamellar pegylated liposomes was evaluated against two human papillary thyroid carcinoma (PTC) cells lines (TPC-1 and B-CPAP) in comparison with the free drug. We found that the liposome encapsulation determines a better uptake of the drug into the cell, resulting in a stronger and earlier cytotoxic effect.

\section{MATERIALS AND METHODS}

\section{Chemicals and Biochemicals}

Gemcitabine hydrochloride (HPLC purity >99\%) was a gift of Eli-Lilly Italia S.p.A. (Sesto Fiorentino, Firenze, Italy) and it was used without further purification. 1,2dipalmitoyl-sn-glycero-3-phospocholine monohydrate (DPPC) and N-(carbonyl-methoxypolyethylene glycol-2000)-1,2distearoyl-sn-glycero-3-phosphoethanolamine (DSPE-MPEG 2000) were purchased from Genzyme (Suffolk, UK). The following products were purchased from Sigma Chemicals Co. (St. Louis, MO, USA), cholesterol (Chol), amphotericin B solution $(250 \mathrm{~g} / \mathrm{ml})$, Hoechst $(500 \mu \mathrm{g} / \mathrm{ml})$ and $\mathrm{N}$-(fluorescein5-tiocarbamoyl)-1,2-dihexadecanoyl-sn-glycero-3-phosphoethanolamine triethylammonium salt (fluorescein-DHPE). DMEM culture medium, fetal bovine serum (FBS), trypsinEDTA $(1 \times)$ solution, Glutamax I complex and penicillinstreptomycin solution were obtained from GIBCO (Invitrogen Corporation, Giuliano Milanese (Mi), Italy). Doubledistilled pyrogen-free water was from Sifra S.p.A. (Verona, Italy). Sterile saline solution was a product of Fresenius Kabi Potenza S.r.l. (Verona, Italy). Human thyroid tumor cell lines TPC-1 and B-CPAP were provided by Prof. A. Fusco (University of Napoli). All other materials and solvents used in this investigation were of analytical grade (Carlo Erba, Milan, Italy).

\section{Preparation of Unilamellar Liposomes}

Liposome composition was made up from DPPC:Chol: DSPE-mPEG $_{2000}(6: 3: 1$ molar ratio). The lipid mixture (40 $\mathrm{mg}$ ) was dissolved in a blend of chloroform/methanol (3:1 $\mathrm{v} / \mathrm{v})$. Fluorescein-labeled liposomes were prepared by codissolving fluorescein-DHPE $(0.1 \%$ molar $)$ with the lipids. Organic solvents were evaporated off under a nitrogen stream using a Rotavapor $^{\circledR}$ (Büchi R-210 Switzerland), thereby obtaining a thin layer phospholipid film along the walls of the pyrex glass tubes. Any trace of residual solvent was eliminated by an overnight storage at room temperature in a Büchi T51 glass drying oven connected to a vacuum pump. A $\mathrm{pH}$ gradient encapsulation technique was used to increase liposome loading capacity [12]. Briefly, lipid films were hydrated with a $250 \mathrm{mM}$ ammonium sulfate solution (1 $\mathrm{ml}$ ) and then submitted to ten cycles of freezing (liquid nitrogen) and thawing (water bath at $40^{\circ} \mathrm{C}$ ), thus achieving a $\mathrm{pH}$ gradient, between the internal and external liposomal environments, with homogenously acid intra-liposomal aqueous compartments. Multilamellar vesicles were then submitted to extrusion through 800,400 and $200 \mathrm{~nm}$ pore size two stacked polycarbonate filters (Costar, Corning Incorporated, NY, USA), at $56^{\circ} \mathrm{C}$ (above the gel-liquid transition temperature of phospholipid mixtures), by using a stainless steel extrusion device (Lipex Biomembranes, Vancouver, BC, Canada) and un-entrapped ammonium sulfate solution was removed by centrifugation. A Beckman Avanti 30 centrifuge equipped with F1202 fixed angle rotor (Beckman Coulter, Fullerton, CA) at $14000 \times \mathrm{g}$ at $4{ }^{\circ} \mathrm{C}$ for $1 \mathrm{~h}$ was used during the experimental procedure. Gemcitabine-loaded small unilamellar liposomes (Gem-L), were obtained by suspending the extruded vesicles in an isotonic solution $(1 \mathrm{ml})$ of gemcitabine hydrochloride $(1 \mathrm{mM})$ and keeping at room temperature for $3 \mathrm{~h}$. Gem-L were then submitted to purification and physiochemical characterization.

\section{Physicochemical Characterization of Liposomes}

Mean size and size distribution (polydispersity index) of unloaded liposomes and Gem-L were evaluated by dynamic light-scattering experiments. Zetasizer NanoZS (Malvern Instruments Ltd., Worchestershire, UK), a photo-correlation spectroscopy apparatus, was used for the dimensional analysis. The instrument is equipped with a $4.5 \mathrm{~mW} \mathrm{He} / \mathrm{Ne}$ laser operating at $670 \mathrm{~nm}$. Experiments were carried out at a scattering angle of $173^{\circ}$ and a third-order cumulant fitting autocorrelation function was applied. A medium refractive index of 1.330 , a medium viscosity of $1.0 \mathrm{mPa} \mathrm{s}$ and a dielectric constant of 80.4 were set as instrumental parameters for light-scattering experiments. Samples were suitably diluted with a filtered (Sartorius membrane filters $0.22 \mu \mathrm{m}$ ) saline solution to avoid multiscattering phenomena and placed in a quartz cuvette. Experiments were carried out at room temperature. Thirty measurements were carried out for each sample. Size and polydispersity index values of the various formulations are the mean of three different preparation batches \pm standard deviation.

\section{Liposome Loading Capacity}

The loading capacity of liposomes was determined by removing the un-entrapped gemcitabine by means of a Beckman Avanti ${ }^{\mathrm{TM}} 30$ Centrifuge $\left(20000 \times \mathrm{g}\right.$ for $1 \mathrm{~h}$ at $\left.4^{\circ} \mathrm{C}\right)$. The gemcitabine contained in the supernatant was determined spectrophotometrically at $\lambda_{\max } 268.8 \mathrm{~nm}$ using a Perkin Elmer Lambda 20 UV-Vis spectrophotometer equipped by a Perkin Elmer UV Win-Lab ${ }^{\mathrm{TM}} 2.8$ acquisition software (Perkin-Elmer GmbH Uberlingen,Germany). The following gemcitabine calibration curve was used:

$$
y=0.6958 \times 10^{-3}+0.3971 x
$$

where $y$ is the absorbance at $268.8 \mathrm{~nm}$ and $x$ is the drug concentration $(\mu \mathrm{M}), \mathrm{r}^{2}$ value was 0.9993 . 
Gemcitabine loading capacity was also evaluated by gel permeation chromatography. The instrument used was an Äkta Prime Plus (Amersham Biosciences, Uppsala, Sweden) equipped with a Sephadex G25 column (Amersham Biosciences). Sterile saline solution, filtered through $0.22 \mu \mathrm{m}$ pore membranes, was used as eluent with a flux of 0.2 $\mathrm{ml} / \mathrm{min}$. The amount of unloaded gemcitabine was determined by the AUC (area under the curve) of the GPCchromatogram (Fig. 1). Gemcitabine loading capacity obtained with this method was quantified using an external standard curve according to the following equation:

$A U C=0.50112 x+0.0484$

where $x$ is the drug concentration $(\mu \mathrm{g} / \mathrm{ml})$ and $A U C$ the area under the curve $(\mathrm{mAu} \times \mathrm{min})$. A linear concentration range between 0.1 and $10 \mu \mathrm{g} / \mathrm{ml}$ was carried out for the construction of the standard curve. A $r^{2}$ value of 0.9996 was obtained by using GPC method.

The amount of drug encapsulated is expressed both as encapsulation yield $(E Y)$ and encapsulation capacity $(E C)$. $E Y$ values were calculated using the following equation:

$E Y=\left[\frac{D t-D u}{D t}\right] \times 100$

where $D t$ is the total amount of the drug used for liposome preparation and $D u$ is the amount of un-entrapped drug. Whereas, $E C$ values were calculated using the following equation:

$E C=\frac{[D e]}{[D a]} \times[L]$

where $[D e]$ is the concentration of the encapsulated drug, $[D a]$ is the concentration of the drug added during liposome preparation and $[L]$ is the total concentration of lipids used for liposome preparation [21]. Concentrations are expressed as $\mu$ moles $/ \mu 1$.

\section{Cell Lines}

TPC-1 and B-CPAP cell lines (from human papillary thyroid cancer) were grown as previously described [22]. Briefly, the cells were cultured in plastic culture dishes $(100$ $\mathrm{mm} \times 20 \mathrm{~mm}$ ) at $37{ }^{\circ} \mathrm{C}$ in a humidified atmosphere with $5 \%$ (v/v) $\mathrm{CO}_{2}$ using D-MEM culture medium supplemented with $10 \% \mathrm{FBS}, 100 \mathrm{U} / \mathrm{ml}$ penicillin, $100 \mu \mathrm{g} / \mathrm{ml}$ streptomycin and Glutamax I complex. The culture medium was changed every $48 \mathrm{~h}$ and cells were detached by trypsin $(2 \mathrm{ml})$ when reaching a $\sim 70 \%$ confluence and harvested in a centrifuge tube, using a Megafuge 1.0 Centrifuge (Haraeus Sepatech Centrifuge) at $1200 \mathrm{rpm}$ for $10 \mathrm{~min}$ at room temperature. The cell pellet was suspended in culture medium and seeded into different culture plates in order to carry out both in vitro viability and mortality assays, which were independent each other.

\section{Evaluation of the In Vitro Antitumor Activity}

TPC-1 and B-CPAP cells were used for cell viability and mortality assay. The two cellular lines were cultured for at most 10 passages and all experiments were performed using cells at passage 5 in the exponential growth phase.

TPC-1 and B-CPAP cell viability was evaluated by MTT-test which is based on the determination of amount of the colored formazan crystals formed during the biological test and proportionally related to the number of viable cells. The cells were plated in 96-well culture dishes $\left(5 \times 10^{3}\right.$ cells $/ 0.2 \mathrm{ml}$ ) and incubated for $24 \mathrm{~h}$ at $37^{\circ} \mathrm{C}$ to promote their adhesion to the plate. The culture medium was then removed, replaced with fresh one containing the different formulations (free or liposomal gemcitabine at a drug concentration of $0.01,0.1,1$ and $10 \mu \mathrm{M})$ and incubated for 24,48 or $72 \mathrm{~h}$. Every plate had 8 wells with untreated cells as the control and 8 wells with cells treated with empty pegylated liposomes as the blank. After treatment, $10 \mu \mathrm{l}$ of MTT (5
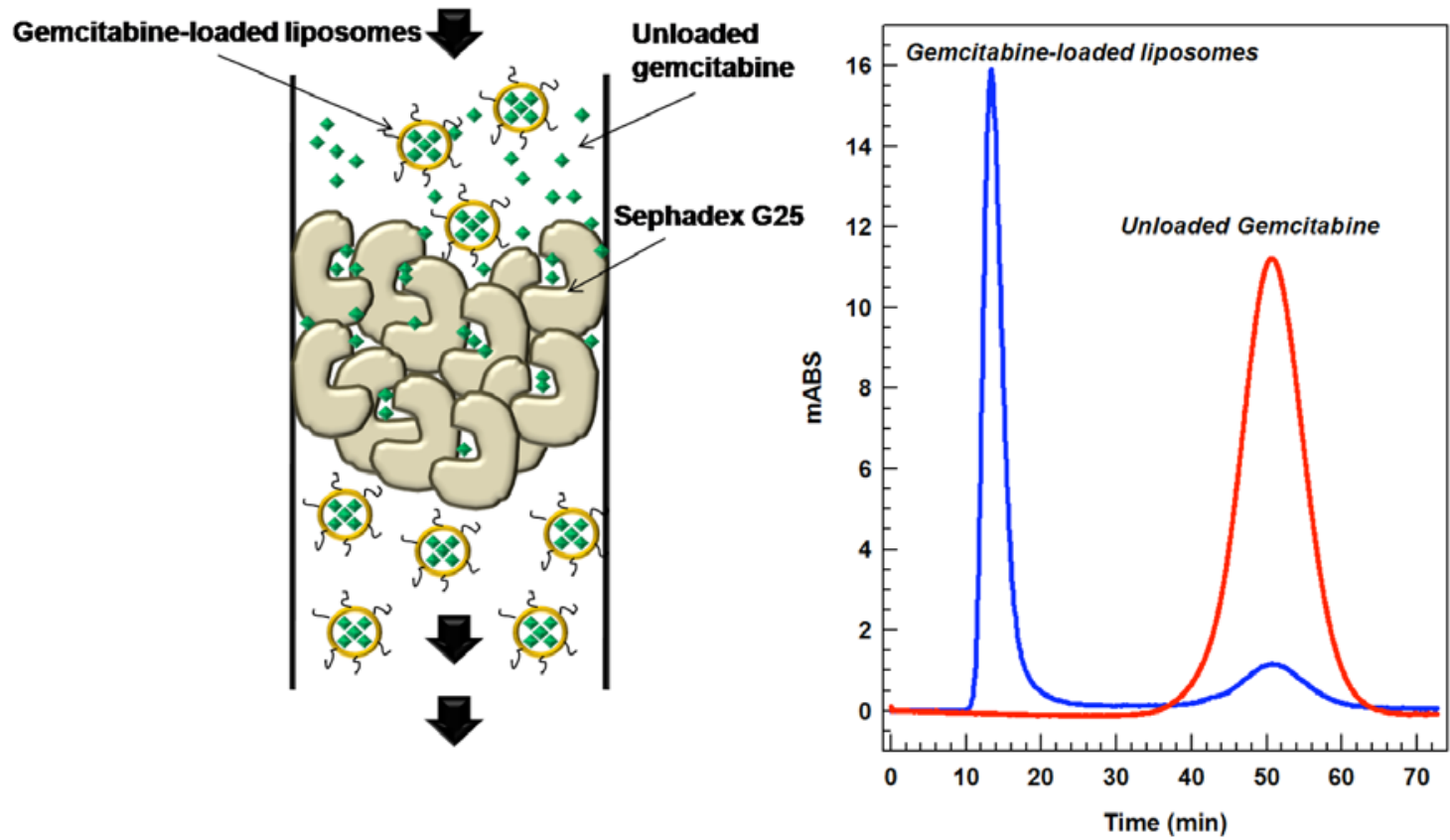

Fig. (1). Schematic representation and typical gel permeation chromatogram of a gemcitabine-loaded unilamellar pegylated liposomes (blue chromatogram) and a simple aqueous drug solution (red chromatogram) at the same concentration used for the liposome preparation. 
$\mathrm{mg} / \mathrm{ml}$ dissolved in PBS solution) were added to each well and incubated for $3 \mathrm{~h}$. Supernatants were removed and 200 $\mu \mathrm{l}$ of a dimethyl sulfoxide/ethanol solution $(1: 1 \mathrm{v} / \mathrm{v})$ were added to dissolve the colored formazan crystals. Plates were then gently shaken at $230 \mathrm{rpm}$ (IKA ${ }^{\circledR}$ KS 130 Control, IKA $^{\circledR}$ WERKE GMBH \& Co, Staufen, Germany) for 20 min. Absorbance of various samples was measured with an ELISA microplate reader (Labsystems mod. Multiskan MS, Midland, ON, Canada) at $570 \mathrm{~nm}$ in absorbance and $670 \mathrm{~nm}$ in emission. The percentage of cell viability was calculated according to the following equation:

$$
\text { Cell from Viability }=\frac{A b s T}{A b s C} \times 100
$$

where $A b s T$ is the absorbance of treated cells and $A b s C$ the absorbance of control (untreated) cells. Cell viability values were the average of six different experiments \pm standard deviation.

TPC-1 and B-CPAP cell mortality was assessed using the trypan blue dye exclusion assay. After treatment with the aforesaid formulations, cells, previously seeded in 12-well culture dishes $\left(1.5 \times 10^{4}\right.$ cells $\left./ \mathrm{ml}\right)$, were detached using Trypsin/EDTA solution $(2 \mathrm{ml})$ and then centrifuged at 1200 rpm for $10 \mathrm{~min}$ (Megafuge 1.0, Heraeus Sepatech) at $22^{\circ} \mathrm{C}$. Supernatants were discarded and cell pellets were resuspended in $200 \mu 1$ of a trypan blue buffer. The number of dead cells was determined by a hematocytometer chamber using an optical microscope (Labophot-2, Nikon, Japan). Dead cell were colored blue. The cellular mortality was calculated according to the following equation:

$$
\text { Cell from Mortality }(\%)=\left[1-\frac{\frac{N t-N d}{N t}}{\frac{N c-N c d}{N c}}\right] \times 100
$$

where $N t$ is the total number of treated cells, $N d$ is the number of dead treated cells colored in blue, $N c$ is the total number of control cells and $N d c$ is the number of dead control cells colored blue. Cell mortality values were the average of six different experiments \pm standard deviation.

\section{Confocal Laser Scanning Microscopy (CLSM)}

The interaction between papillary thyroid carcinoma cells and fluorescein-DHPE $(0.1 \%$ molar ratio) labelled pegylated unilamellar liposomes $(100 \mu 1$ for each well) was evaluated by CLSM. In particular, the cells were placed in 6-well culture plates $\left(3 \times 10^{4}\right.$ cells $\left./ \mathrm{ml}\right)$ with culture medium. In each well a sterile glass slide was previously positioned. Plates were incubated for $24 \mathrm{~h}$ and then cells were treated with liposomes for $6 \mathrm{~h}$. After incubation, each well was washed with PBS (3 times) to remove the excess of vesicles and cells were fixed on the sterile glass slides by using $1 \mathrm{ml}$ of an ethanol solution $(70 \% \mathrm{v} / \mathrm{v})$. Each slide glass was washed again with PBS three times. Each well was treated with $1 \mathrm{ml}$ of Hoechst solution (1/1000), incubated for $30 \mathrm{~min}$ and then washed three times with PBS $(2 \mathrm{ml})$. Slide glasses were positioned on cover-glass by using a glycerol solution $(70 \% \mathrm{v} / \mathrm{v})$ to remove enclosed air and then were fixed by a transparent glue. The analysis was carried out using a Leika TCS SP2 MP laser scanning confocal microscope at a $\lambda_{\text {exc }}=496 \mathrm{~nm}$ and a $\lambda_{\mathrm{em}}=519 \mathrm{~nm}$ for fluorescein probe and at a $\lambda_{\mathrm{exc}}=405$ $\mathrm{nm}$ and a $\lambda_{\mathrm{em}}=460 \mathrm{~nm}$ for Hoechst probe. A scan resolution up to $4096 \times 4096$ pixels with an $\mathrm{Ar} / \mathrm{Kr}$ laser beam of 75
$\mathrm{mW}$, equipped with a fluorescein analyzer filter, was used for experimental investigations. Samples were recorded by a macro developer software package having multi-dimensional series acquisition and direct-access digital control knobs. An immersion oil lens $100 \times$ was used.

\section{Statistical Analysis}

Statistical analysis of the various experimental results was performed by using one-way ANOVA. A posteriori Bonferroni t-test was carried out to check the ANOVA test. A $p$ value $<0.05$ was considered statistically significant. All the values are reported as the average \pm standard deviation.

\section{RESULTS AND DISCUSSION}

\section{Liposomal Characterization}

The liposomal carrier can provide a passive drug targeting towards a large variety of solid tumors, which are characterized by the presence of discontinuous structure, at the level of the endothelium of tumor capillaries, formed by the neoangiogenic process [23]. These fenestrations have diameters ranging from $800 \mathrm{~nm}$ to $100 \mathrm{~nm}$. Therefore an important parameter to be fulfilled for a suitable use of the liposomal carrier as an anticancer drug delivery system is a reduced mean size.

Thus, we first performed an extrusion through polycarbonate membranes obtaining the reduction of the liposome mean size from $\sim 800 \mathrm{~nm}$ to $\sim 100 \mathrm{~nm}$ and the transformation of the liposomal system from multilamellar to unilamellar (Table 1), using the protocol described by Berger and coworkers [24]. The extrusion process also allowed the formation of liposome colloidal suspensions characterized by a homogeneous size distribution, as evidenced by a 0.02 polydispersity index value (Table 1). The presence of gemcitabine did not significantly influence the liposome mean size. Moreover, the analysis of the zeta potential (Table 1) showed the presence of a slight negative charge on the surface of the small unilamellar liposomes. The zeta potential values were much lower (as absolute values) than those expected [25], due to the presence of PEG moieties along the liposome surface, which shield the polar head group of phospholipids and reduce the electrophoretic mobility of the colloidal vesicles. Also in this case, the presence of gemcitabine determined no significant effect on the liposome surface charge.

Table 1. Formulation Parameters of Unloaded and Gemcitabine-Loaded Liposome Colloidal Suspensions Made up of DPPC/Chol/DSPE-MPEG2000 (6:3:1 Molar Ratio) $)^{\mathrm{a}}$

\begin{tabular}{|c|c|c|}
\hline Parameter & Empty SUV $^{\mathbf{c}}$ & GEM-SUV $^{\mathbf{c}}$ \\
\hline \hline Mean size (nm) & $207.4 \pm 5.2$ & $213.2 \pm 6.4$ \\
\hline Polydispersity index & $0.027 \pm 0.011$ & $0.025 \pm 0.009$ \\
\hline Loading capacity (\%) $^{\mathrm{b}}$ & - & $93.3 \pm 1.2$ \\
\hline
\end{tabular}

${ }^{a}$ Each value is the average of five different experiments \pm SD.

${ }^{\mathrm{b}}$ The loading capacity is expressed as the percentage of the amount of gemcitabine used during liposome preparation that become entrapped. The obtained value is referred to the use of centrifugation method.

${ }^{\mathrm{c}} \mathrm{SUV}$ indicates pegylated small unilamellar vesicles. 
The loading capacity is a very important parameter for the evaluation of the potential therapeutic use of a drug delivery system. The presence of an aminic protonable group in the molecule of gemcitabine, allows to increase the liposomal drug encapsulation following the generation of $\mathrm{pH}$ gradient inside liposomes. This method lead to an effective drug entrapment (Fig. 1) characterized by an $E Y$ value of $94 \%$ and an $E C$ value of $14 \mu 1 / \mu \mathrm{mol}$. The $E C$ value was much higher than that expected for unilamellar liposomes [26]. This finding may be due to two different factors: i) the precipitation of the drug molecule as sulfate salt (used for the generation of the acid $\mathrm{pH}$ gradient) in aqueous compartments of unilamellar liposomes and/or ii) the interaction of gemcitabine with the molecules of phospholipids [27]. Both factors can lead to an overestimation of the aqueous volume entrapped within unilamellar liposomes and hence of the liposomal gemcitabine encapsulation parameters ( $E Y$ and $E C$ values).

\section{In Vitro Antitumor Activity}

The antitumor activity of the novel pharmaceutical preparations containing four different concentrations of gemcitabine $(0.01,0.1,1$ and $10 \mu \mathrm{M})$ were compared with free drug against two different papillary thyroid carcinoma cell lines, TPC-1 and B-CPAP cells. The two cell lines are widely used as model of this type of cancer as they host the most frequent genetic alterations found in human PTC in vivo: RET/PTC rearrangement in TPC-1 and V600E BRAF mutation in BCPAP respectively, detected with mutual exclusion in about half of PTCs [28]. Such genetic alterations are related to a different clinical behaviour, more aggressive for the tumors hosting the BRAF mutations [29]; thus suggesting that the two cell lines are the best preclinical in vitro model to test the effects of novel potential drugs in view of a targeted therapy.

As shown in Figs. (2) and (3), the free drug inhibited the cell proliferation, determining a significant increase of mortality, which was maximal after $72 \mathrm{~h}$ incubation and a drug concentration of $10 \mu \mathrm{M}$. The responses were similar between the two cell lines investigated and comparable with those observed in other thyroid cell lines in previous reports $[10,11]$. For both papillary thyroid carcinoma cell lines and in all experiments, we used as control untreated cells which showed a mortality rate always $\leq 1.5 \%$ and unchanged cell viability. Moreover, cells treated with unloaded liposomes showed similar values to controls (data not reported).

Interestingly, a different trend was observed after the encapsulation of the hydrophilic drug inside the vesicular carrier. In particular, gemcitabine-loaded liposomes exerted their effects at early incubation time and at lower dosage with respect to the free drug. In TPC-1 cells (Fig. 2), at a drug concentration of $1 \mu \mathrm{M}$, after $48 \mathrm{~h}$ incubation, liposomal gemcitabine elicited a reduction of cell vitality of $\sim 35 \%$ with respect to $20 \%$ of the free drug. At the same concentration and after $72 \mathrm{~h}$ treatment, gemcitabine-loaded liposomes provided also a significant improvement of the TPC-1 cell mortality ( 60\%) regarding to the free drug ( 40\%) (Fig. 2). A similar cytotoxic profile was observed in the B-CPAP cells (Fig. 3). In particular, after 24 and $48 \mathrm{~h}$ incubation, the colloidal devices caused a bland improvement of the anti-

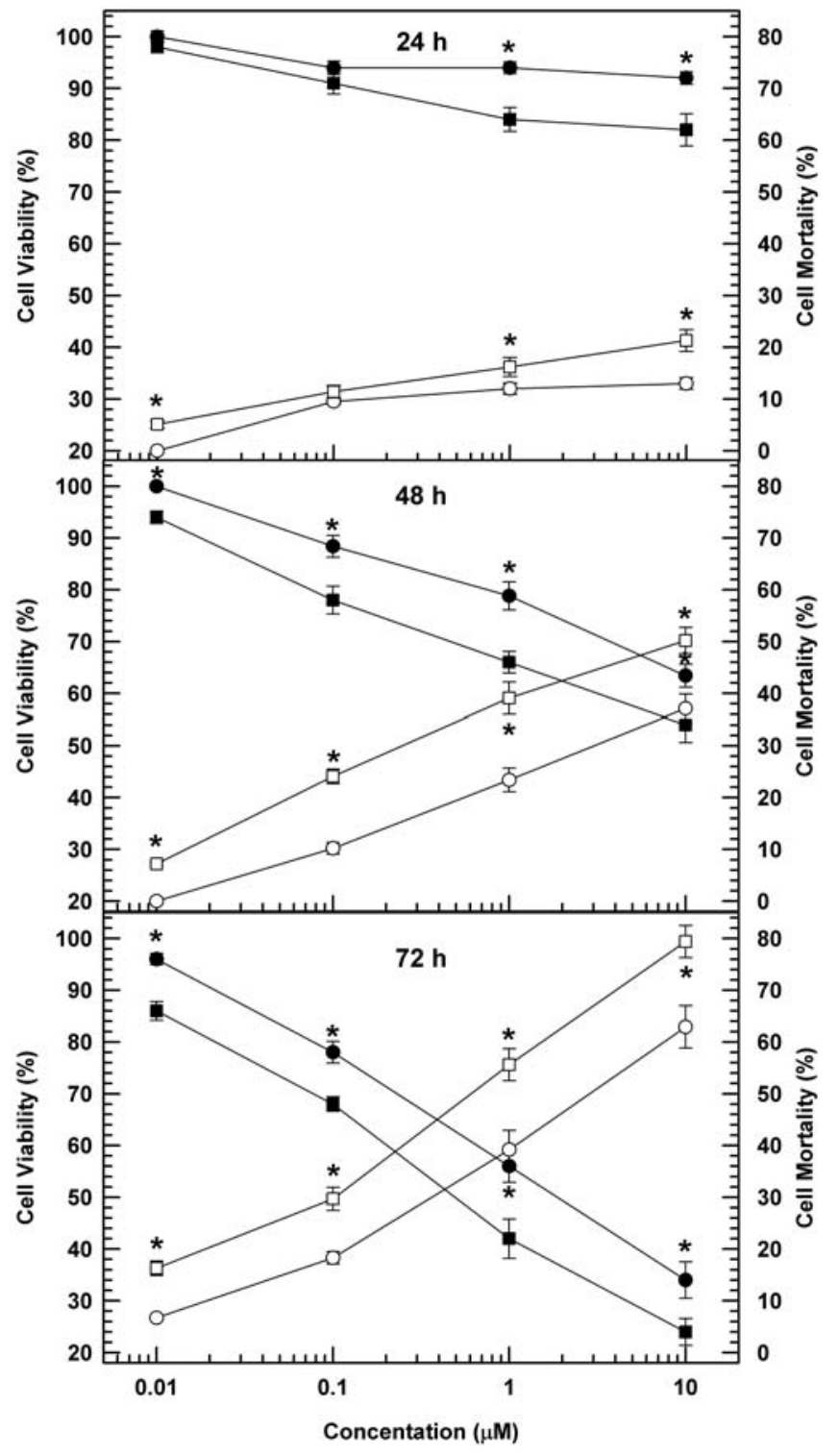

Fig. (2). Dose-dependent cytotoxic effect of free gemcitabine $(\mathbf{0}, \mathrm{O})$ or gemcitabine-loaded pegylated unilamellar liposomes $(\boldsymbol{\square}, \square)$ against TPC-1 human papillary thyroid cancer cells as a function of the exposition time. Drug cytotoxic effect is expressed both as cell viability (filled symbols, MTT test) and cell mortality (hollow symbols, trypan bleu dye exclusion assay). Error bars, if not shown, are within symbols. Results are presented as the mean of six different experiments \pm standard deviation. *, ANOVA statistical analysis showed $\mathrm{p}$ values $<0.005$.

tumor effect of the active compound $(\geq 10 \%)$ with respect to the free form at low drug concentrations $(0.01$ and $0.1 \mu \mathrm{M})$, while at a higher dosage $(1$ and $10 \mu \mathrm{M})$ the difference of mortality was more appreciable. Moreover, after $72 \mathrm{~h}$ incubation, the variation in terms of reduction of cell vitality between them become more marked. For example, at a drug concentration of $1 \mu \mathrm{M}$, liposomal formulation induced a cell mortality of about $50 \%$ with respect to the $30 \%$ caused by the free form; while, at the concentration $10 \mu \mathrm{M}$, the difference was increased ( $80 \%$ vs $45 \%$, respectively) (Fig. 3). 


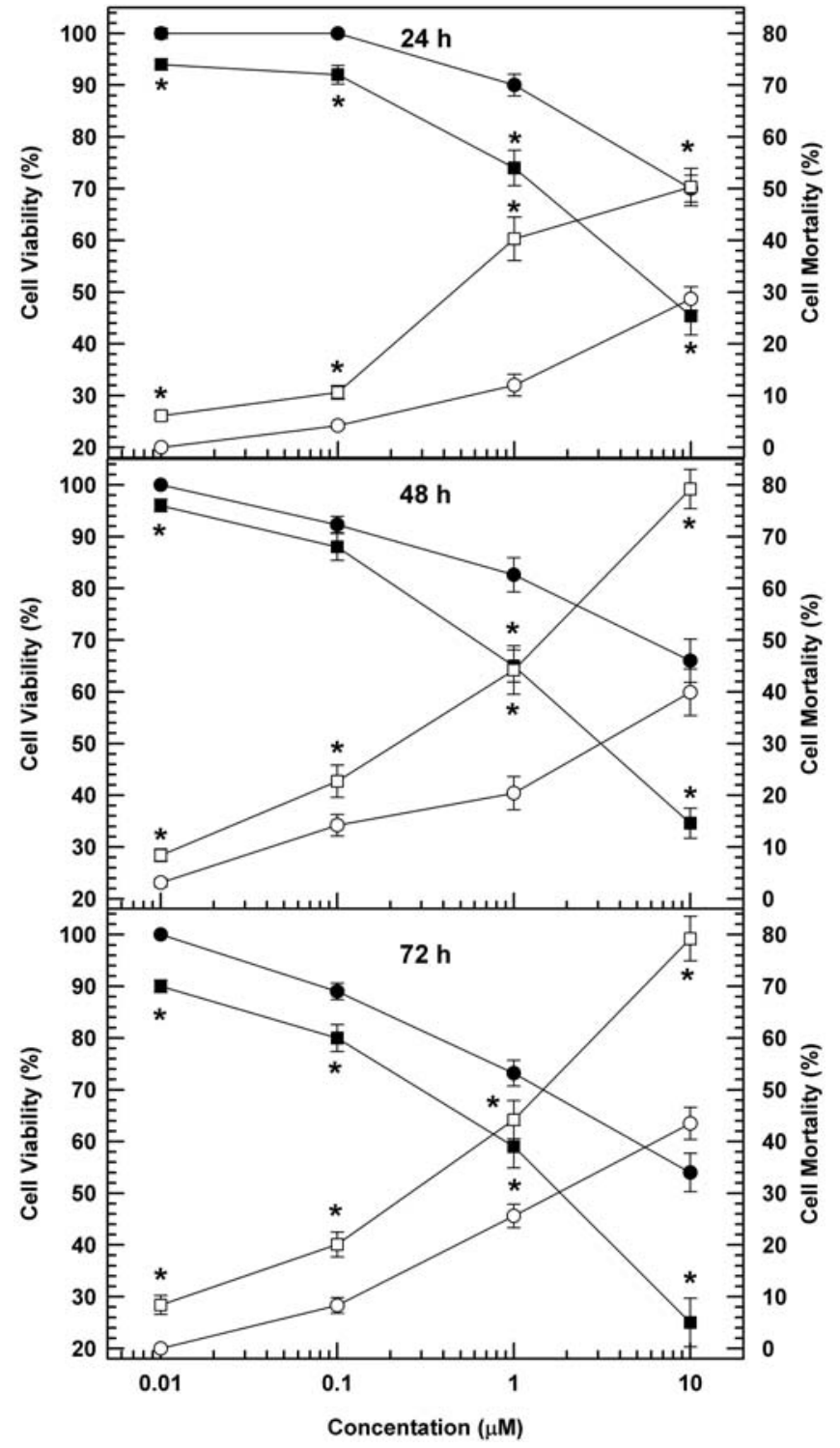

Fig. (3). Dose-dependent cytotoxic effect of free gemcitabine $(\bullet, \bigcirc)$ or gemcitabine-loaded pegylated unilamellar liposomes $(\boldsymbol{\square}, \square)$ against B-CPAP human papillary thyroid cancer cells as a function of the exposition time. Drug cytotoxic effect is expressed both as cell viability (filled symbols, MTT test) and cell mortality (hollow symbols, trypan bleu dye exclusion assay). Error bars, if not shown, are within symbols. Results are presented as the mean of six different experiments \pm standard deviation. *, ANOVA statistical analysis showed $\mathrm{p}$ values $<0.005$.

\section{Evaluation of carrier/cell interaction}

Experimental investigations were also performed to evaluate if the improved cytotoxic effect of the liposomal gemcitabine formulation with respect to the conventional drug saline solution was related to a greater cellular internalization of this active compound mediated by the liposomal carrier. This hypothesis was tested by confocal laser scanning microscopy experiments. B-CPAP cells were incubated for $6 \mathrm{~h}$ with fluorescein-labeled liposomes and their interaction rate was evaluated. Hoechst probe was used to evidence the cellular nuclei (Fig. 4 panel A) while untreated cells were detected in transmission mode because their

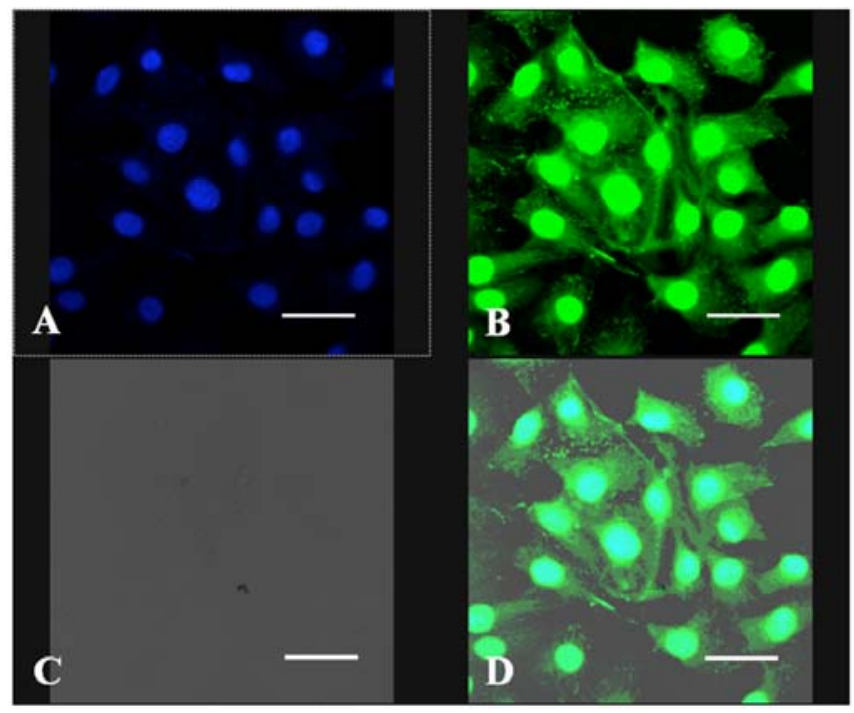

Fig. (4). CLSM micrographs of B-CPAP cells treated with fluorescein-labelled pegylated unilamellar liposomes after $6 \mathrm{~h}$ incubation. Panel A: Hoechst filter; panel B: FITC filter; panel C: transmission mode; panel D: overlay. Bar $=30 \mu \mathrm{m}$.

intrinsic fluorescence was too low at the wavelengths used for marker detection (Fig. 4 panel C). After $6 \mathrm{~h}$ incubation the liposomal vesicular carriers were disseminated in all cellular compartments (Fig. 4 panel B). In particular, it was interesting to note the presence of colloidal devices at the level of both cellular membranes and cytoplasm, as a consequence of the direct interaction of liposomal carriers and the cells. As schematically shown in Fig. (5), this phenomenon may be related to the ability of liposomes to be internalized after fusion or/and occurring of an endocytotic mechanism. In any case, both processes allow the improvement of drug concentration inside the cells that is responsible of their death, while free gemcitabine needs of nucleoside transporters, resulting in a lower and less efficient intake [30-32]. Similar results were observed in TPC-1 cells (data not shown).

\section{CONCLUSIONS}

Finally, our findings clearly demonstrate that the encapsulation of gemcitabine in pegylated unilamellar liposomes improves the cytotoxic effect of the drug on different papillary thyroid carcinoma cells with respect to the free form, suggesting a more effective drug uptake inside them. These observations confirm the validity of liposomes, and in particular the unilamellar formulations as carriers for anticancer drugs, as further demonstrated by reports exploiting in vivo experimental models [33-36]. Further studies, using xenograft models of thyroid cancer, will provide additional information to test the liposomal-encapsulated gemcitabine in clinical trials of patients with recurrent and metastatic PTC refractory to the current treatments.

\section{ACKNOWLEDGEMENTS}

This work was financially supported by grants from the MIUR Cofin 2005 Program (Prof. Diego Russo), the MIUR PRIN 2006 Program (Prof. Massimo Fresta), and the Italian Ministery of Health - Regione Calabria (Dipartimento 


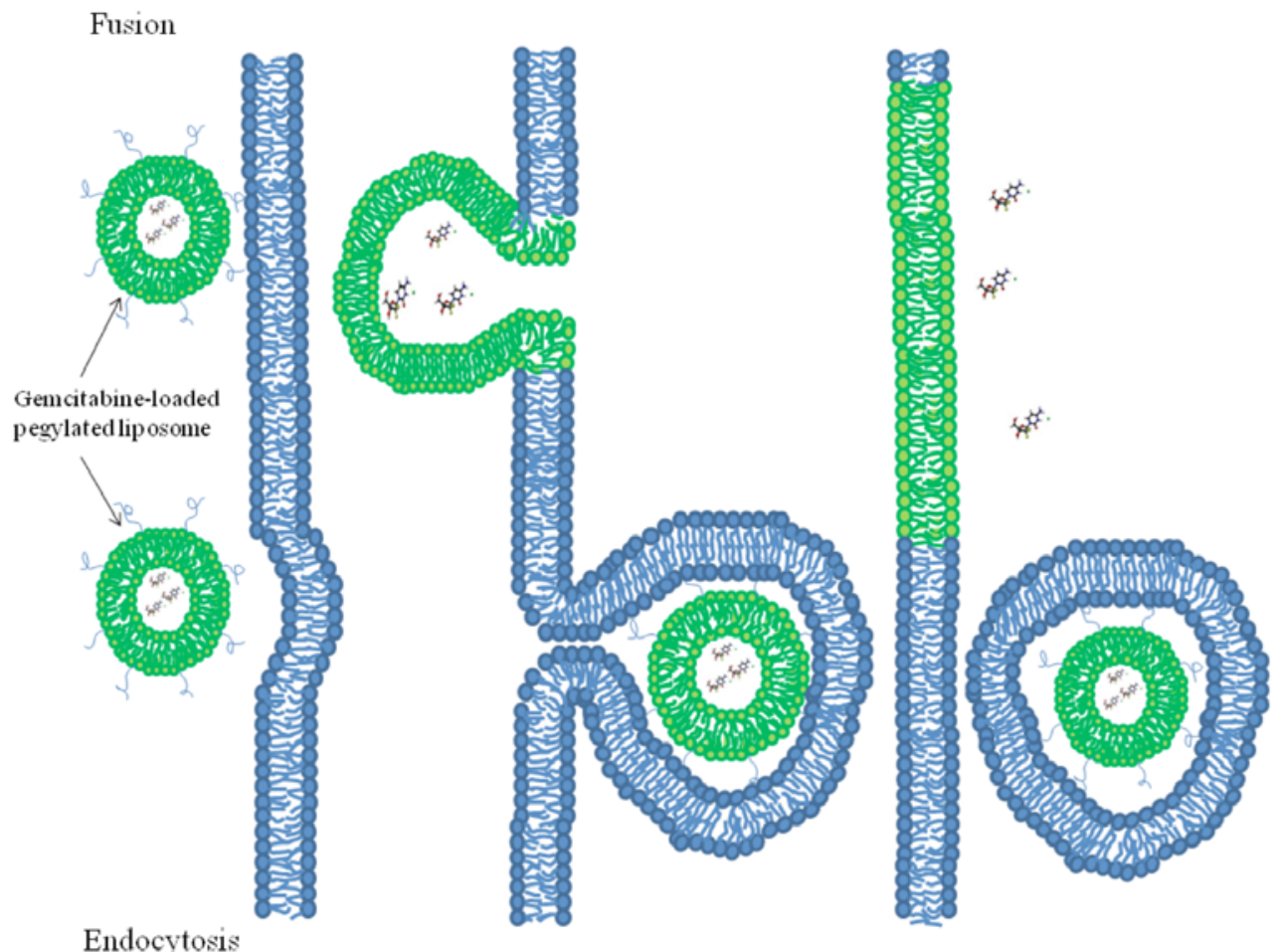

Fig. (5). Schematic representation of the possible interaction of fluorescein-labeled gemcitabine-loaded pegylated unilamellar liposomes with human papillary thyroid cancer cells.

Tutela della Salute Politiche Sanitarie e Sociali). The authors are very grateful to Dr. Lynn Whitted for her revision of the language of this manuscript.

\section{REFERENCES}

[1] Sherman, S.I. Thyroid carcinoma. Lancet, 2003, 8, 501-511.

[2] Davies, L.; Welch, H.G. Increasing incidence of thyroid cancer in the United States, 1973-2002. JAMA, 2006, 295, 2164-2167.

[3] Pelizzo, M.R.; Merante, B.I.; Toniato, A.; Pagetta, C.; Casal, Ide, E.; Mian, C.; Rubello, D. Diagnosis, treatment, prognostic factors and long-term outcome in papillary thyroid carcinoma. Minerva Endocrinol., 2008, 33, 359-379.

[4] Filetti, S.; Bidart, J.M.; Arturi, F.; Caillou, B.; Russo, D.; Schlumberger, M. Sodium/Iodide Symporter (NIS): a key transport system in thyroid cancer cell metabolism. Eur. J. Endocrinol., 1999, 141, 443-457.

[5] Schlumberger, M.; Lacroix, L.; Russo, D.; Filetti, S.; Bidart, J.M. Defects in iodide metabolism in thyroid cancer and implications for the follow-up and treatment of patients. Nat. Clin. Pract. Endocrinol. Metab., 2007, 3, 260-269.

[6] Arturi, F.; Russo, D.; Giuffrida, D.; Schlumberger, M.; Filetti, S. Sodium-Iodide symporter (NIS) gene expression in lymph node metastases of papillary thyroid carcinomas. Eur. J. Endocrinol, 2000, 143, 623-627.

[7] Haugen, B.R. Management of the patient with progressive radioiodine non-responsive disease. Semin. Surg. Oncol., 1999, 16, 34-41.

[8] Woyach, J.A.; Shah, M.H. New therapeutic advances in the management of progessive thyroid cancer. Endocr. Rel. Cancer, 2009, 16, 715-731.

[9] Reddy, L.H.; Couvreur, P. Novel approaches to deliver gemcitabine to cancers. Curr. Pharm. Des., 2008, 14, 1124-1137.

[10] Ringel, M.D. Molecular diagnostic tests in the diagnosis and management of thyroid carcinoma. Rev. Endocr. Metab. Disord., 2000, 1, 173-181.

[11] Celano, M.; Calvagno, M.G.; Bulotta, S.; Paolino, D.; Arturi, F.; Rotiroti, D.; Filetti, S.; Fresta, M.; Russo, D. Cytotoxic effects of gemcitabine-loaded liposomes in human anaplastic thyroid carcinoma cells. BMC Cancer, 2004, 4, 63.

[12] Fritze, A.; Hens, F.; Kimpfler, A.; Schubert, R.; Peschka-Süss, R. Remote loading of doxorubicin into liposomes driven by a trans- membrane phosphate gradient. Biochim. Biophys. Acta, 2006, $1758,1633-1640$.

[13] Voigt, W.; Kegel, T.; Weiss, M.; Mueller, T.; Simon, H.; Schmoll, H.J. Potential activity of paclitaxel, vinorelbine and gemcitabine in anaplastic thyroid carcinoma. J. Cancer Res. Clin. Oncol., 2005, 131, 585-590.

[14] Abratt, R.P. Gemcitabine hydrochloride: combination of activity and tolerability (Summary). Anticancer Drugs, 1995, 6, 63-64.

[15] Immordino, M.L.; Brusa, P.; Rocco, F.; Arpicco, S.; Ceruti, M.; Cattel, L. Preparation, characterization, cytotoxicity and pharmacokinetics of liposomes containing lipophilic gemcitabine prodrugs. J. Control. Release, 2004, 100, 331-346.

[16] Myhren, F.; Borretzen, B.; Dalen, A.; Sandvold, M. Gemcitabine derivative. WO patent 32762, 1998.

[17] Pasut, G.; Canal, F.; Dalla Via, L.; Arpicco, S.; Veronese, F. M.; Schiavon, O. Antitumoral activity of PEG-gemcitabine prodrugs targeted by folic acid. J. Control. Release, 2008, 127, 239-248.

[18] Celia, C.; Malara, N.; Terracciano, R.; Cosco, D.; Paolino, D.; Fresta, M.; Savino, R. Liposomal delivery improves the growthinhibitory and apoptotic activity of low doses of gemcitabine in multiple myeloma cancer cells. Nanomedicine, 2008, 4, 155-166.

[19] Cosco, D.; Bulotta, A.; Ventura, M.; Celia, C.; Calimeri, T.; Perri, G.; Paolino, D.; Costa, N.; Neri, P.; Tagliaferri, P.; Tassone, P.; Fresta, M. In vivo activity of gemcitabine-loaded PEGylated small unilamellar liposomes against pancreatic cancer. Cancer Chemother. Pharmacol., 2009, 64, 1009-1020.

[20] Celia, C.; Calvagno, M.G.; Paolino, D.; Bulotta, S.; Ventura, C.A.; Russo, D.; Fresta, M. Improved in vitro anti-tumoral activity, intracellular uptake and apoptotic induction of gemcitabine-loaded pegylated unilamellar liposomes. J. Nanosci. Nanotechnol., 2007, 8, $1-12$.

[21] Calvagno, M.G., Celia, C.; Paolino, D.; Cosco, D.; Iannone, M.; Castelli, F.; Doldo, P.; Fresta, M. Effects of lipid composition and preparation conditions on physical-chemical properties, technological parameters and in vitro biological activity of gemcitabineloaded liposomes. Curr. Drug Deliv., 2007, 4, 89-101.

[22] Puppin, C.; D’Aurizio, F.; D’Elia, A.V.; Cesaratto, L.; Tell, G., Russo, D.; Filetti, S.; Ferretti, E.; Tosi, E.; Mattei, T.; Pianta, A.; Pellizzari, L.; Damante, G. Effects of histone acetylation on NIS promoter and expression of thyroid-specific transcription factors. Endocrinology, 2005, 146, 3967-3974. 
[23] Decuzzi, P.; Causa, F.; Ferrari, M.; Netti, P.A. The effective dispersion of nanovectors within the tumor microvasculature. Ann. Biomed. Eng., 2006, 34, 633-641.

[24] Berger, N.; Sachse, A.; Bender, J.; Schubert, R.; Brandl, M. Filter extrusion of liposomes using different devices: comparison of liposome size, encapsulation efficiency, and process characteristics. Int. J. Pharm., 2001, 223, 55-68.

[25] Fresta, M.; Ricci, M.; Rossi, C.; Furneri, P.M.; Puglisi, G. Antimicrobial nonapeptide leucinostatin-A: dependent effects on the physical properties of phospholipid model membranes. J. Colloid Interface Sci., 2000, 226, 222-230.

[26] Diaz, R.S.; Monreal, J.; Regueiro, P.; Lucas, M. Preparation of a protein-free total brain white matter lipid fraction: characterization of liposomes. Neurosci. Res., 1992, 31, 136-145.

[27] Castelli, F.; Raudino, A.; Fresta, M. A mechanistic study of the permeation kinetics through biomembrane models: gemcitabinephospholipid bilayer interaction. J. Colloid Interface Sci., 2005, 285, 110-117.

[28] Finn, S.; Smyth, P.; O’Regan, E.; Cahill, S.; Toner, M.; Timon, C.; Flavin, R.; O'Leary, J.; Sheils, O. Low-level genomic instability is a feature of papillary thyroid carcinoma: an array comparative genomic hybridization study of laser capture microdissected papillary thyroid carcinoma tumors and clonal cell lines. Arch. Pat. Lab. Med., 2007, 131, 65-73.

[29] Puxeddu, E.; Durante, C.; Avenia, N.; Filetti, S.; Russo, D. Clinical implications of BRAF mutation in thyroid carcinoma. Trends Endocrinol. Metab., 2008, 19, 138-145.

[30] Griffith, D.A.; Jarvis, S.M. Nucleoside and nucleobase transport systems of mammalian cells. Biochim. Biophys. Acta, 1996, 1286, 153-181.
[31] Griffiths, M.; Beaumont, N.; Yao, S.Y.; Sundaram, M.; Boumah, C.E.; Davies, A.; Kwong, F.Y.; Coe, I.; Cass, C.E.; Young, J.D.; Baldwin, S.A. Cloning of a human nucleoside transporter implicated in the cellular uptake of adenosine and chemotherapeutic drugs. Nat. Med., 1997, 3, 89-93.

[32] Oguri, T.; Achiwa, H.; Muramatsu, H.; Ozasa H.; Sato, S.; Shimizu, S.; Yamazaki, H.; Eimoto, T.; Ueda, R. The absence of human equilibrative nucleoside transporter lexpression predicts nonresponse to gemcitabine-containing chemotherapy in non-small cell lung cancer. Cancer Lett., 2007, 256, 112-119.

[33] Celano, M.; Schenone, S.; Cosco, D.; Navarra, M.; Puxeddu, E.; Racanicchi, L.; Brullo, C.; Varano E.; Alcaro, S.; Ferretti, E.; Botta, G.; Filetti, S.; Fresta, M.; Botta, M.; Russo, D. Cytotoxic effects of a novel pyrazolopyrimidine derivative entrapped in liposomes in anaplastic thyroid cancer cells in vitro and in xenograft tumors in vivo. Endocr. Rel. Cancer, 2008, 15, 499-510.

[34] Gorumlu, G.; Kucukzeybek, Y.; Kemal-Gul, M.; Karaca, B.; Cosan-Terek, M.; Karabulut, B.; Sanli, U.A.; Akman, L.; Ozsaran, A.; Dikmen, Y.; Uslu, R. Pegylated liposomal doxorubicin in heavily pretreated epithelial ovarian cancer patients. J. BUON., 2008, 13, 349-352.

[35] Airoldi, M.; Cattel, L.; Milla, P.; Pedani, F.; Garzaro, M.; Dosio, F. Paclitaxel and pegylated liposomal doxorubicin in recurrent head and neck cancer: clinical and unexpected pharmacokinetic interactions. Anticancer Res., 2008, 28, 2519-2527.

[36] Zhang, Y.; Li, A.; Wang, Z.; Han, Z.; He, J.; Ma, J. Antimetastatic activities of pegylated liposomal doxorubicin in a murine metastatic lung cancer model. J. Drug Target., 2008, 16, 679-687.

Received: April 18, 2010

Revised: June 18, 2010

Accepted: June 27, 2010

(C) Vono et al.; Licensee Bentham Open.

This is an open access article licensed under the terms of the Creative Commons Attribution Non-Commercial License (http://creativecommons.org/licenses/by-nc/3.0/) which permits unrestricted, non-commercial use, distribution and reproduction in any medium, provided the work is properly cited. 